\title{
Approaches to Control Nitrate Pollution in the San Joaquin Watershed
}

\author{
Stephen Clayton and Misgana Muleta \\ Department of Civil and Environmental Engineering, California Polytechnic State \\ University, San Luis Obispo
}

\section{Extended Abstract}

Modeling of the San Joaquin valley using SWAT can give a comprehensive overview of hydrologic traits of the San Joaquin River and its tributaries, specifically for nutrients like nitrate. The San Joaquin valley is a site of intense modeling interest and policy making, as the San Joaquin River joins the Sacramento River to feed into the Delta. The environmental impact of dissolved oxygen on aquatic life on the Delta is a particularly key concern (Quinn 2000). The San Joaquin watershed also represents considerable investment in agriculture on the valley floor and has been studied for nitrate, sediment, and salinity concerns particularly with regard to agricultural runoff. Evaluation of model accuracy and utility are important for any future studies on the San Joaquin River for hydrology and nutrients, especially in regards to policy making. Criteria for model evaluation are based on model accuracy and reliable conclusions on the watershed traits. The accuracy of the model is summarized by the goodness-of-fit (e.g., NashSutcliffe efficiency, mean of sum of square residuals), as well as the ability of the model to reproduce trustworthy results. Reliable conclusions concerning the hydrological simulation of the San Joaquin are based on recognizable hydrology trends in surface flow and nutrient origin and transport, particularly nitrates.

Models are a tool used by engineers for a better understanding and explanation of natural phenomena and may provide predictions in a deterministic or probabilistic sense (Ritter 2001). Models simplify real life scenarios and situations. If models are used correctly, with the proper understanding of the utility as well as the flaws of modeling, they can sufficiently represent reality to justify decisions and formulate policies. Many hydrologic models, models which try to represent hydrologic conditions through the use of physical laws and mechanistic approaches, have been developed for research, management, and regulation for Water Resources Engineering purposes. Developing public and water stakeholder trust in hydrology models is important for model use in decision making and policy support, which is essential for emerging water management problems like urban water supply reliability, environmental restoration, climate change, floods, and agricultural water security. California's complex water system depends on how well the water community develops and uses data and models to address these water management problems (CWEMF, 2005).

SWAT is an example of a water resources model potentially useful for Best Management Practices (BMP). The Soil and Water Assessment Tool (SWAT) is an extension of the ArcGIS program. The SWAT model is robust and computationally efficient, representing 30 years of modeling efforts under the direction of the United States Department of Agriculture (USDA) Agriculture Research Service (ARS). SWAT is used by the Environmental Protection Agency (EPA) in their Better Assessment Science Integrating Point and Nonpoint Sources (BASINS) software package, and has been assessed by over 250 peer-reviewed published articles (Gassman, 2007). SWAT is capable of simulating weather, hydrology, soil processes, nutrient transport, and land management. Continuing investment in SWAT validation indicates the need for 
implementation, linking policy making to stakeholder trust in model validation. SWAT has already been studied as a method of modeling nitrate (Stewart et al. 2006, Chaplot et al. 2004, Bracmort et al. 2006, Gassman, 2007), but not for the San Joaquin watershed.

Although nitrate nitrogen is an essential plant nutrient, it is considered a water pollutant in excess and is therefore monitored by the EPA with a Maximum Contaminant Level (MCL) of $10 \mathrm{mg} / \mathrm{L}$ (EPA). A high nitrate level in drinking water is particularly unsafe for infants, the elderly, and young animals when the nitrate converts to nitrite in the digestive tract, causing methemoglobinemia (also known as blue baby syndrome) ( $\mathrm{Ng}$ et al. 2000). Excess nitrogen can occur from agricultural runoff, where supplemental nitrogen is applied to maximize crop yield. Thus the San Joaquin valley is a prime candidate for nitrate monitoring, where nutrients have been linked to algae growth and the dissolved oxygen sag in the delta (Quinn 2005) and nitrate and uranium pose the greatest threats to the long term sustainability of the ground water resources in the eastern San Joaquin Valley (Jurgens 2008).

SWAT models the complexity of the nitrogen cycle in the water, atmosphere, and soil, and includes the soil profile and the shallow aquifer. Nitrogen processes like nitrification, denitrification, ammonia volatization, and leaching can be calibrated by various nutrient parameters during the calibrating process (Neitsch, 2005). A calibrated watershed model for flow and sediments is a necessary precursor to nutrient calibration. An initial delineation of the watershed according to the combined datasets of the Digital Elevation Model (DEM), land use dataset, and soil classification (STATSGO), gave 55 subbasins with the selection of the Vernalis monitoring site (\#11303500) as the outlet. Further classification for modeling purposes produced 370 Hydrologic Response Units, in order to represent segments of watershed which lend the same hydrologic response. Four reservoirs nestled in the foothills on the eastern side of the San Joaquin valley (New Melones, Don Pedro, Millerton, and Exchequer) were included in the model to help account for sediment and nutrient retention and simulate reservoir release rates.

A sensitivity analysis using the Latin-Hypercube (LH) and One-factor-At-a-Time (OAT) method will be conducted for the time period 1993-2000 for the various parameter sets corresponding to flow, snowmelt, sediment, and nutrients. Based on observed data from water gages on the San Joaquin and its tributaries, a parameter ranking will help determine which parameters should be included in the calibration. The sets of calibration and validation for the same time period as the sensitivity analysis are to be snowmelt, surface flow, sediment content, and nitrate concentration, according to gage stations suggested in Luo 2008. These gage stations will include the Vernalis monitoring outlet and a water monitoring gage upstream of the reservoirs. Including several stages of calibration, one or more for each measured output, helps distinguish model accuracy and validation for each of these output variables. The calibration process is based on a global optimization procedure called Shuffled Complex Evolution Algorithm (SCE-UA), and has been widely used in watershed model calibration (Liew 2010).

Known hydrologic trends for the San Joaquin River will provide the framework for model validation and evaluation. Modeled flow outputs should resemble known surface flow trends, such as $70 \%$ of total flow measured at Vernalis coming from the Sierra Nevada region (Quinn 2002). Similarly, nutrient origin and transport can be compared to previous nutrient studies (Saleh 2007), which assure that the drainage from 
the Mud and Salt Sloughs accounts for nearly half of the nitrate in the San Joaquin (Stringfellow 2008).

\section{References}

Bracmort, K. S., M. Arabi, J. R. Frankenberger, B. A. Engel, and J. G. Arnold. 2006. Modeling long term water quality impact of structural BMPs. Trans. ASABE 49(2): 367-374.

California Water and Environmental Modeling Forum. 2005 "A Strategic analysis Framework for Managing Water in California.” 3 Jan 2012.

Chaplot, V., A. Saleh, D. B. Jaynes, and J. Arnold. 2004. Predicting water, sediment, and NO3-N loads under scenarios of land use and management practices in a flat watershed Water Air Soil Pollut. 154(1-4): 271-293.

Domagalski, Joseph L., and Neil M. Dubrovsky. "Pesticide residues in ground water of the San Joaquin Valley, California.” Journal of Hydrology 130.1-4 (1992): 299338. Web. 3 Jan. 2012.

EPA Webcast <http://water.epa.gov/learn/training/wacademy/upload/2011_03_29_slides.pdf>

Gassman, P.W., Reyes, M.R., Green, C.H., and Arnold, J.G.(2007). "The Soil and Water Assessment Tool: Historical Development, Applications, and Future Research Directions.” Transactions of the ASABE, 50(4), 1211-1250.

Jurgens, Bryant C., Burow, Karen R., Dalgish, Barbara A., and Shelton, Jennifer L. 2008. Hydrogeology, Water Chemistry, and Factors Affecting the Transport of Contaminants in the Zone of Contribution of a Public-Supply Well in Modesto, Eastern San Joaquin Valley, California Scientific Investigations Report 5156

Luo, Yuzhou, Xuyang Zhang, Xingmei Liu, Darren Ficklin, and Minghua Zhang. "Dynamic Modeling of Organophosphate Pesticide Load in Surface Water in the Northern San Joaquin Valley Watershed of California." Environmental Pollution 156.3 (2008): 1171-181. Print.

Neitsch, S.L., Arnold, J.G., Kiniry, J.R., Williams, J.R.(2005). “Soil and Water Assessment Tool-Version 2005-Theoretical Documentation”, Temple, Texas, USA.

Ng, H.Y.F et al. "Modeling and testing of the effect of tillage, cropping and water management practices on nitrate leaching in clay loam soil.” Agricultural Water Management 43.1 (2000): 111-131. Web. 17 Jan. 2012.

Stewart, G. R., C. L. Munster, D. M. Vietor, J. G. Arnold, A. M. S. McFarland, R. White, and T. Provin. 2006. Simulating water quality improvements in the upper North Bosque River watershed due to phosphorus export through turfgrass sod. Trans. ASABE 49(2): 357-366.

Stringfellow, William T. et al. "Comparison of wetland and agriculture drainage as sources of biochemical oxygen demand to the San Joaquin River, California." Agricultural Water Management 95.5 (2008): 527-538. Web. 3 Jan. 2012.

Quinn N.W.T. , C.W. Chen and W.T. Stringfellow. 2000. A Decision Support System for Real-Time Management of Dissolved Oxygen in the Stockton Deep Water Ship Channel. Environmental Software Systems. Environmental Information and Decision Support. IFIP TC5 WG5.11, 5th International Symposium on Environmental Software Systems (ISESS'2000), May 28-June 2, 2000 Austria. 
Quinn, N.W.T. et al. 2005. "Elements of a decision support system for real-time management of dissolved oxygen in the San Joaquin River Deep Water Ship Channel.” Environmental Modelling \& Software 20.12: 1495-1504. Web. 3 Jan. 2012.

Quinn, N.W.T., Tulloch, Alice. 2002. San Joaquin River Diversion Data Assimilation, Drainage Estimation and Installation of Diversion Monitoring Stations. CALFED Bay-Delta Program.

Ritter, William F., and Adel Shirmohammadi. Agricultural Nonpoint Source Pollution: Watershed Management and Hydrology. Boca Raton, FL: Lewis, 2001. Print.

Van Liew, M.W., Veith, T.L. 2010. Guidelines for using sensitivity analysis and auto calibration tools for multi-gage or multi-step calibration in SWAT. 